Check for updates

Cite this: J. Mater. Chem. C, 2019, 7, 3543

Received 10th November 2018, Accepted 25th February 2019

DOI: $10.1039 / \mathrm{c} 8 \mathrm{tc} 05658 \mathrm{~g}$

rsc.li/materials-c

\section{Fluorescence-based histamine sensing with inorganic-organic hybrid nanoparticles}

\author{
B. Lilli Neumeier, Joachim G. Heck and Claus Feldmann (D) *
}

\begin{abstract}
Four novel inorganic-organic hybrid nanoparticles ( $\mathrm{OH}-\mathrm{NPs}$ ) are presented that allow a fluorescence detection of biogenic amines such as histamine. Namely, the $1 \mathrm{OH}-\mathrm{NPs}$ are $\mathrm{Cu}^{2+}[\mathrm{Calc}]^{2-}, \mathrm{Ag}_{2}{ }^{+}[\mathrm{Calc}]^{2-}$ (Calc: calcein, $\mathrm{C}_{30} \mathrm{H}_{24} \mathrm{~N}_{2} \mathrm{O}_{13}$ ), $\mathrm{Cu}_{2}{ }^{2+}[\mathrm{PTC}]^{4-}$ and $\mathrm{Ag}_{4}{ }^{+}$[PTC] ${ }^{4-}$ (PTC: perylenetetracarboxylate, $\mathrm{C}_{24} \mathrm{H}_{8} \mathrm{O}_{8}$ ) that contain extremely high dye loads of calcein $\left(90 \mathrm{wt} \%\right.$ in $\mathrm{Cu}^{2+}[\mathrm{Calc}]^{2-}, 70 \mathrm{wt} \%$ in $\mathrm{Ag}_{2}{ }^{+}[\mathrm{Calc}]^{2-}$ ) and of the perylene derivative (77 wt\% in $\mathrm{Cu}_{2}{ }^{2+}[\mathrm{PTC}]^{4-}, 50 \mathrm{wt} \%$ in $\mathrm{Ag}_{4}{ }^{+}[\mathrm{PTC}]^{4-}$ ). The saline compounds are prepared by water-based synthesis, which instantaneously results in highly stable nanoparticle suspensions. Whereas the calcein- and perylenetetracarboxylate-related fluorescence is essentially quenched in the solid nanoparticles, the respective dye is released into solution in the presence of histamine and, thereafter, shows bright emission with an intensity depending on the concentration of histamine. Specifically, $\mathrm{Ag}_{4}{ }^{+}[\mathrm{PTC}]^{4-}$ shows promising performance with high colloidal and chemical stability as well as a remarkable concentration-depending fluorescence increase upon addition of histamine (e.g. 180-times higher emission upon addition of $100 \mu \mathrm{M}$ of histamine). In fact, only $\mathrm{Ag}_{4}{ }^{+}[\mathrm{PTC}]^{4-} \mathrm{IOH}-\mathrm{NPs}$ show off/on-like emission in the absence/presence of histamine, which is preferable for reliable fluorescence detection.
\end{abstract}

\section{Introduction}

Allergies represent a widespread disease in modern industrial societies affecting $20-30 \%$ of the population. ${ }^{1}$ The underlying hypersensitivity originates from a misregulation of the immune system with cause-effect relationships that are often unknown. Most relevant allergens include animal products (e.g. dust mite excretion), drugs (e.g. penicillin), food (e.g. peanuts), insect stings (e.g. wasp stings), and pollen (e.g. birch). The detection of allergic reactions and the differentiation from other acute diseases in hospitals or emergency medicine is often tedious and difficult. Current in vivo provocation tests are often slow and not without risk for the patient. However, reliable and fast detection of allergic reactions is essential to avoid an acute anaphylactic shock and a potentially deadly risk for the patient. $^{2}$

Many hypersensitivity reactions (so-called type I allergens) relate to the formation of allergen-specific IgE antibodies with an altered immune response due to a shifted T-helper cell type 1/type 2 (T1-T2) equilibrium. Whereas a T1-dominated immune response is observed in healthy individuals, the immune response is dominated by T2 in the case of an allergy. ${ }^{3}$ Several mediators such as histamine, serotonin, leukotrienes, heparin and

Institut für Anorganische Chemie, Karlsruhe Institute of Technology (KIT), Engesserstrasse 15, 76131 Karlsruhe, Germany. E-mail: claus.feldmann@kit.edu; Fax: +49-721-60844892; Tel: +49-721-60842855 various enzymes are known to indicate such allergic reactions. They are predominantly released by basophils and mast cells within minutes after the contact to the allergen. ${ }^{4}$ Therefore, detection of the mediators can be highly indicative to prove allergic reactions and will be preferably performed ex vivo.

Several test systems for allergy diagnostics are available that either address the released mediators (histamine, leukotrienes, tryptase, etc.) or vesicle proteins on the cell surface after degranulation. ${ }^{5}$ As a straightforward strategy, fluorescence-based histamine detection was suggested, too. ${ }^{6}$ Practicability, reliability, and specifity, however, were yet assessed unsatisfactory. ${ }^{7}$ To improve the overall performance, an increase of the emission and a more pronounced differentiation of absence and presence of histamine were already named desirable. ${ }^{7}$

Nanoparticles are of increasing importance for all kinds of imaging techniques as well as for in vitro and in vivo studies in general. ${ }^{8}$ In particular, optical imaging (OI) and magnetic resonance imaging (MRI) benefitted significantly from nanoparticlebased concepts. ${ }^{9}$ Specifically, fluorescent and/or magnetic nanoparticles allow to unveil organ distribution with deep tissue information and to improve contrast and spatial resolution. ${ }^{8,9}$ Aiming at allergy diagnostics, nanoparticles have been barely addressed by now and relate to complex, multi-component strategies such as histamine-binding to specific polymers inducing a fluorescence response, ${ }^{10}$ or histamine-binding inducing a shift of the plasmon resonance of $\mathrm{Ag}$ or $\mathrm{Au}$ nanoparticles. ${ }^{11}$ In this regard, we here suggest saline inorganic-organic hybrid 
nanoparticles (IOH-NPs) $\mathrm{Cu}^{2+}[\mathrm{Calc}]^{2-}, \mathrm{Ag}_{2}{ }^{+}\left[\mathrm{Calc}^{2-}, \mathrm{Cu}_{2}{ }^{2+}[\mathrm{PTC}]^{4-}\right.$ and $\mathrm{Ag}_{4}{ }^{+}[\mathrm{PTC}]^{4-}$ (Calc: calcein, PTC: perylenetetracarboxylate) for ex vivo fluorescence detection of histamine. Specific advantages of the IOH-NPs as novel materials comprise: (i) straightforward aqueous synthesis; (ii) extraordinarily high dye load of 50 to $90 \mathrm{wt} \%$; (iii) tremendous increase of emission intensity in the presence of histamine.

\section{Experimental section}

\subsection{Synthesis}

$\mathrm{Cu}^{2+}[\mathrm{Calc}]^{2-}$ IOH-NPs (Calc: Calcein, $\left.\mathrm{C}_{30} \mathbf{H}_{24} \mathbf{N}_{2} \mathbf{O}_{13}\right) \cdot \mathrm{Na}_{n}(\mathrm{Calc})$ $(n=2-3)$ (100 mg, $0.15 \mathrm{mmol}$, ABCR) was dissolved in $200 \mathrm{~mL}$ of water and heated to $55{ }^{\circ} \mathrm{C}$ with vigorous stirring. Thereafter, an aqueous solution $(0.5 \mathrm{~mL})$ containing $\mathrm{Cu}\left(\mathrm{NO}_{3}\right)_{2} \times 3 \mathrm{H}_{2} \mathrm{O}(32 \mathrm{mg}$, $0.14 \mathrm{mmol}$, Aldrich, 99.9\%) was injected. After $10 \mathrm{~min}$ of intense stirring, the as-prepared nanoparticles were separated via centrifugation $(25000 \mathrm{rpm}, 15 \mathrm{~min})$. For purification, the orange IOH-NPs were resuspended in and centrifuged from $\mathrm{H}_{2} \mathrm{O}$ twice. The $\mathrm{Cu}^{2+}[\mathrm{Calc}]^{2-} \mathrm{IOH}$-NPs can be resuspended in $\mathrm{H}_{2} \mathrm{O}$, PBS buffer or dextran solution via mechanical stirring or ultrasonification to obtain colloidally stable suspensions with a content of up to $3 \mathrm{mg} \mathrm{mL}{ }^{-1}$. In alternative, the IOH-NPs can be dried in a drying oven at $60{ }^{\circ} \mathrm{C}$ to obtain powder samples.

$\mathbf{A g}_{2}{ }^{+}[\mathrm{Calc}]^{2-}$ IOH-NPs. $\mathrm{Na}_{n}(\mathrm{Calc})(n=2-3,100 \mathrm{mg}, 0.15 \mathrm{mmol})$ was dissolved in water $(100 \mathrm{~mL})$. Under total exclusion of light an aqueous solution $(0.5 \mathrm{~mL})$ containing $\mathrm{Ag}\left(\mathrm{NO}_{3}\right)(69 \mathrm{mg}, 0.41 \mathrm{mmol}$, Aldrich, $\geq 99 \%$ ) was injected at room temperature. After stirring overnight, the as-obtained IOH-NPs were separated via centrifugation $(25000 \mathrm{rpm}, 15 \mathrm{~min})$. The red $\mathrm{Ag}_{2}{ }^{+}[\mathrm{Calc}]^{2-}$ IOH-NPs were purified in darkness by twice resuspending in and centrifuging from $\mathrm{H}_{2} \mathrm{O}$. The IOH-NPs can be resuspended as described for $\mathrm{Cu}^{2+}[\mathrm{Calc}]^{2-}$. Due to their light sensitivity, the samples should be stored in darkness. In contrast to $\mathrm{Cu}^{2+}[\mathrm{Calc}]^{2-}$ and $\mathrm{Ag}_{4}[\mathrm{PTC}]^{4-}$, furthermore, $\mathrm{Ag}_{2}{ }^{+}[\mathrm{Calc}]^{2-}$ needs to be dried at $0{ }^{\circ} \mathrm{C}$ by freeze drying to avoid any thermal decomposition with formation of elemental silver.

$\mathrm{Cu}_{2}{ }^{2+}[\mathrm{PTC}]^{4-}$ IOH-NPs (PTC: perylenetetracarboxylate, $\mathrm{C}_{24} \mathrm{H}_{8} \mathrm{O}_{8}$ ). Perylene-3,4,9,10-tetracarboxylic dianhydride (PTCDA, $25 \mathrm{mg}$, $0.06 \mathrm{mmol}, \mathrm{C}_{24} \mathrm{H}_{8} \mathrm{O}_{6}, \mathrm{ABCR}, 98 \%$ ) was suspended in $100 \mathrm{~mL}$ of water. Thereafter, $1 \mathrm{~mL}$ of $1 \mathrm{M} \mathrm{NaOH}$ was added to transform the insoluble cyclic dianhydride into the soluble tetracarboxylate. Upon stirring for 1 hour at $60{ }^{\circ} \mathrm{C}$ a bright yellow, transparent solution was obtained. After adjusting the $\mathrm{pH}$ to 8 with $\mathrm{HNO}_{3}$, an aqueous solution $(0.5 \mathrm{~mL})$ containing $\mathrm{Cu}\left(\mathrm{NO}_{3}\right)_{2} \times 3 \mathrm{H}_{2} \mathrm{O}(26 \mathrm{mg}, 0.10 \mathrm{mmol})$ was injected. After $10 \mathrm{~min}$ of intense stirring, the as-prepared orange $\mathrm{Cu}_{2}{ }^{2+}[\mathrm{PTC}]^{4-}$ IOH-NPs were separated by centrifugation $(25000 \mathrm{rpm}$, $15 \mathrm{~min})$. They can be purified and resuspended as described before.

$\mathbf{A g}_{4}^{+}[\text {PTC }]^{4-}$ IOH-NPs. $\mathrm{Ag}_{4}{ }^{+}[\mathrm{PTC}]^{4-}$ was prepared similarly to the $\mathrm{Cu}_{2}{ }^{2+}[\mathrm{PTC}]^{4-}$ IOH-NPs. Instead of $\mathrm{Cu}\left(\mathrm{NO}_{3}\right)_{2} \times 3 \mathrm{H}_{2} \mathrm{O}$, an aqueous solution $(0.5 \mathrm{~mL})$ of $\mathrm{AgNO}_{3}(36 \mathrm{mg}, 0.21 \mathrm{mmol})$ was injected. After $10 \mathrm{~min}$ of intense stirring, the as-prepared orange $\mathrm{Ag}_{4}^{+}[\mathrm{PTC}]^{4-}$ IOH-NPs were separated via centrifugation
(25000 rpm, $15 \mathrm{~min}$ ). They can be purified and resuspended as described before. In contrast to the above mentioned $\mathrm{Ag}_{2}{ }^{+}[\mathrm{Calc}]^{2-} \mathrm{IOH}-\mathrm{NPs}, \mathrm{Ag}_{4}{ }_{4}^{+}[\mathrm{PTC}]^{4-}$ is not sensitive to daylight. Storing for several weeks did not result in any formation of elemental silver.

\subsection{Analytical tools}

Dynamic light scattering (DLS) was used to determine the hydrodynamic diameter of the IOH-NPs in suspension. Measurements were conducted in polystyrene cuvettes applying a Nanosizer ZS (Malvern Instruments, United Kingdom).

Zeta potential measurements were conducted using an automatic titrator MPT-2 attached to the aforementioned Nanosizer ZS. Titrations were performed by addition of $0.1 \mathrm{M} \mathrm{HCl}$ or $0.1 \mathrm{M} \mathrm{NaOH}$.

Scanning electron microscopy (SEM) was performed with a Zeiss Supra 40 VP (Zeiss, Germany), equipped with a fieldemission gun and a resolution of $1.3 \mathrm{~nm}$ (at $15 \mathrm{kV}$ ). Due to the organics content, the IOH-NPs are highly sensitive to the electron beam and decompose due to local charging and heating. To minimize sample decomposition, examinations were performed at 5 to $15 \mathrm{kV}$. Samples were prepared by placing a droplet of a diluted aqueous suspension of the IOH-NPs on a silica wafer that was left for drying overnight.

Energy-dispersive X-ray (EDX) analysis was performed with an Ametek EDAX device (Ametek, USA), mounted on the above described Zeiss SEM Supra 40 VP. To this purpose, the IOH-NPs were pressed to dense pellets in order to obtain samples with a smooth surface and a quasi-infinite layer thickness. These pellets were fixed by conductive carbon pads on aluminium sample holders. EDX was used to validate the presence of copper and silver in the IOH-NPs. A quantification of copper and silver and a determination of the lighter elements $\mathrm{C} / \mathrm{N} / \mathrm{O} / \mathrm{H}$ could not be performed due to the limited significance of the method in the case of light elements.

X-ray powder diffraction (XRD) was conducted on a Stadi-P diffractometer (Stoe, Germany) with Ge-monochromatized $\mathrm{Cu}-\mathrm{K} \alpha$ radiation. Dried IOH-NP samples were fixed between Scotch tape and acetate paper and measured between $2^{\circ}$ and $70^{\circ}$ 2-theta.

Fourier-transformed infrared (FT-IR) spectra were recorded on a Bruker Vertex 70 FT-IR spectrometer (Bruker, Germany) in the range of $4000-450 \mathrm{~cm}^{-1}$. To this concern, $1 \mathrm{mg}$ of the dried sample was pestled with $300 \mathrm{mg}$ of dried $\mathrm{KBr}$ and pressed to a pellet that was analysed in transmission.

Differential thermal analysis/thermogravimetry (DTA/TG) was performed with a STA409C device (Netzsch, Germany). All measurements were performed in air. The pre-dried IOH-NP samples $\left(20 \mathrm{mg}\right.$, corundum crucibles) were heated to $1000{ }^{\circ} \mathrm{C}$ with a heating rate of $5 \mathrm{~K} \mathrm{~min}^{-1}$.

Elemental analysis (EA) (C/H/N/S analysis) was performed via thermal combustion with an Elementar Vario Microcube device (Elementar, Germany) at a temperature of about $1100{ }^{\circ} \mathrm{C}$.

Photoluminescence (PL) was recorded with a Horiba Jobin Yvon Spex Fluorolog 3 (Horiba Jobin Yvon, France) equipped with a $450 \mathrm{~W}$ Xe-lamp and double grating excitation and 
emission monochromators. All spectra were measured with $1.5 \mathrm{~nm}$ slit. Excitation was performed at $492 \mathrm{~nm}$ for calceincontaining samples and at $467 \mathrm{~nm}$ for PTC-containing samples. All measurements were carried out 5 min after the addition of histamine.

\section{Results and discussion}

\subsection{Inorganic-organic hybrid nanoparticles}

The IOH-NPs $\mathrm{Cu}^{2+}[\mathrm{Calc}]^{2-}, \mathrm{Ag}_{2}{ }^{+}[\mathrm{Calc}]^{2-}, \mathrm{Cu}_{2}{ }^{2+}[\mathrm{PTC}]^{4-}$ and $\mathrm{Ag}_{4}{ }^{+}[\mathrm{PTC}]^{4-}$ (Calc: calcein, PTC: perylenetetracarboxylate) were prepared by injecting an aqueous solution of $\mathrm{Cu}\left(\mathrm{NO}_{3}\right)_{2} \times 3 \mathrm{H}_{2} \mathrm{O}$ or $\mathrm{AgNO}_{3}$ to an aqueous solution of $\mathrm{Na}_{n}$ (Calc) $(n=2-3)$ or perylene-3,4,9,10-tetracarboxylic dianhydride (PTCDA) at about $60{ }^{\circ} \mathrm{C}$. The synthesis compares to our previously presented concept of phosphate-based IOH-NPs with a general composition $[\mathrm{ZrO}]^{2+}\left[\mathrm{R}_{\text {Function }} \mathrm{OPO}_{3}\right]^{2-}$ (Fig. 1a). ${ }^{12}$ Herein, the inorganic cation $[\mathrm{ZrO}]^{2+}$ and a functional organic anion $\left[\mathrm{R}_{\text {Function }} \mathrm{OPO}_{3}\right]^{2-}$ form a saline hybrid material. The $[\mathrm{ZrO}]^{2+}$ cation in combination with the phosphate-type functional organic anion guarantees the insolubility of the IOH-NPs (Fig. 1a). In addition, sulfonate-type functional organic anions could be introduced in the IOH-NP concept as well. ${ }^{13}$ Based on different functional organic anions, a wide range of IOH-NPs entailing various functionalities such as fluorescence, magnetism or pharmaceutical activity can be realized so that the IOH-NPs become suitable for multimodal imaging and/or drug release. ${ }^{14}$

For the first time, we can now expand the material concept of the IOH-NPs to carboxylate-type functional organic anions as well as to fluorescence detection of histamine with potential application in allergy diagnostics. ${ }^{15}$ In difference to phosphateand sulfonate-type functional organic anions, ${ }^{12-14}$ carboxylate-type functional organic anions such as $[\mathrm{Calc}]^{2-}$ and $[\mathrm{PTC}]^{4-}$ were made insoluble in water upon addition of $\mathrm{Cu}^{2+}$ or $\mathrm{Ag}^{+}$as the inorganic cation (Fig. 1c). Since both are known as harmful to animate beings, in vitro (cell assays) and especially ex vivo application are intended. A specific advantage of the IOH-NP concept is related to the unprecedentedly high dye loads with $90 \mathrm{wt} \%$ and $70 \mathrm{wt} \%$ of calcein in $\mathrm{Cu}^{2+}[\mathrm{Calc}]^{2-}$ and $\mathrm{Ag}_{2}{ }^{+}[\mathrm{Calc}]^{2-}$ as well as a perylene content of $77 \mathrm{wt} \%$ and $50 \mathrm{wt} \%$ in $\mathrm{Cu}_{2}{ }^{2+}[\mathrm{PTC}]^{4-}$ and $\mathrm{Ag}_{4}^{+}[\mathrm{PTC}]^{4-}$.

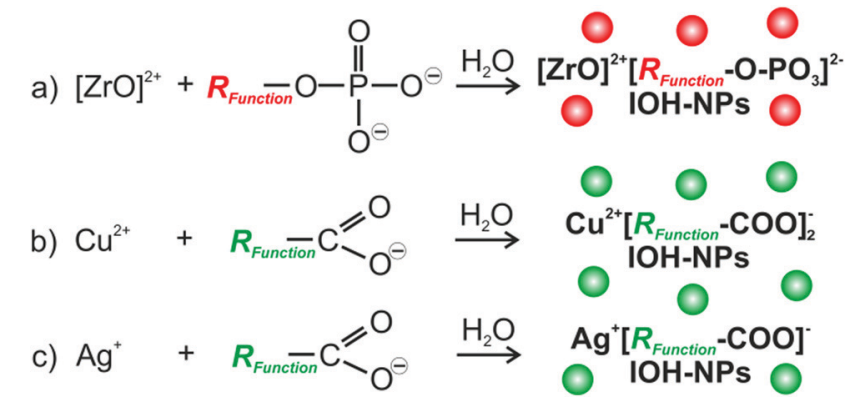

Fig. 1 Synthesis concept of inorganic-organic hybrid nanoparticles (IOH-NPs): (a) phosphate-type functional organic anion with $[\mathrm{ZrO}]^{2+}$ as inorganic cation; (b and c) carboxylate-type functional organic anions with $\mathrm{Cu}^{2+}$ or $\mathrm{Ag}^{+}$as inorganic cations.
To obtain colloidally stable suspensions of the saline $\mathrm{Cu}^{2+}[\mathrm{Calc}]^{2-}, \mathrm{Ag}_{2}{ }^{+}[\mathrm{Calc}]^{2-}, \mathrm{Cu}_{2}{ }^{2+}[\mathrm{PTC}]^{4-}$ and $\mathrm{Ag}_{4}{ }^{+}[\mathrm{PTC}]^{4-} \mathrm{IOH}-\mathrm{NPs}$, particle nucleation and particle growth have to be considered following the LaMer-Dinegar model. ${ }^{16}$ Thus, the synthesis was performed at slightly elevated temperature $\left(60^{\circ} \mathrm{C}\right)$ to support the endothermal nucleation with certain anion access (5-10 mol\%) to guarantee anion-terminated particle surfaces. Furthermore, rapid mixing of the reactants (injection) fosters an instantaneous supersaturation and nucleation. Due to the insolubility in water and due to anion termination, uniform and colloidally stable nanoparticles can be directly obtained in water. Additional stabilizing agents are not required, which significantly facilitates the synthesis.

\section{$3.2 \mathrm{Cu}^{2+}[\mathrm{Calc}]^{2-}$ IOH-NPs}

$\mathrm{Cu}^{2+}[\mathrm{Calc}]^{2-}$ IOH-NPs - as our first example - contain calcein as a well-known, less harmful fluorescent dye ${ }^{6 a-c}$ showing green emission $\left(\lambda_{\max }: 517 \mathrm{~nm}\right)$. The IOH-NPs were prepared by the above described aqueous synthesis upon injecting a solution of $\mathrm{Cu}\left(\mathrm{NO}_{3}\right)_{2} \times 3 \mathrm{H}_{2} \mathrm{O}$ into a solution of $\mathrm{Na}_{n}(\mathrm{Calc})(n=2-3)$ (Fig. 2a). Size and size distribution of the IOH-NPs in aqueous suspension were examined by dynamic light scattering (DLS) resulting in a mean hydrodynamic diameter of $40 \pm 7 \mathrm{~nm}$ at narrow size distribution (Fig. 2b). Scanning electron microscopy (SEM) confirms the presence of spherical nanoparticles with a mean diameter of $27 \pm 8 \mathrm{~nm}$ (calculated by statistical evaluation of 100 particles) (Fig. 2c). The hydrodynamic diameter (from DLS) is larger as the value obtained by SEM due to the rigid solvent shell, which is comparably large due to the high polarity and considerable hydrogen bonding of water as a solvent.

Zeta potential measurements indicate a zeta potential of around $-40 \mathrm{mV}$ in a $\mathrm{pH}$ range of $4-9$ (Fig. 2d). This negative surface charging explains the excellent colloidal stability of the as-prepared aqueous IOH-NP suspensions. In this regard, a zeta potential below $-30 \mathrm{mV}$ or above $+30 \mathrm{mV}$ is typically considered
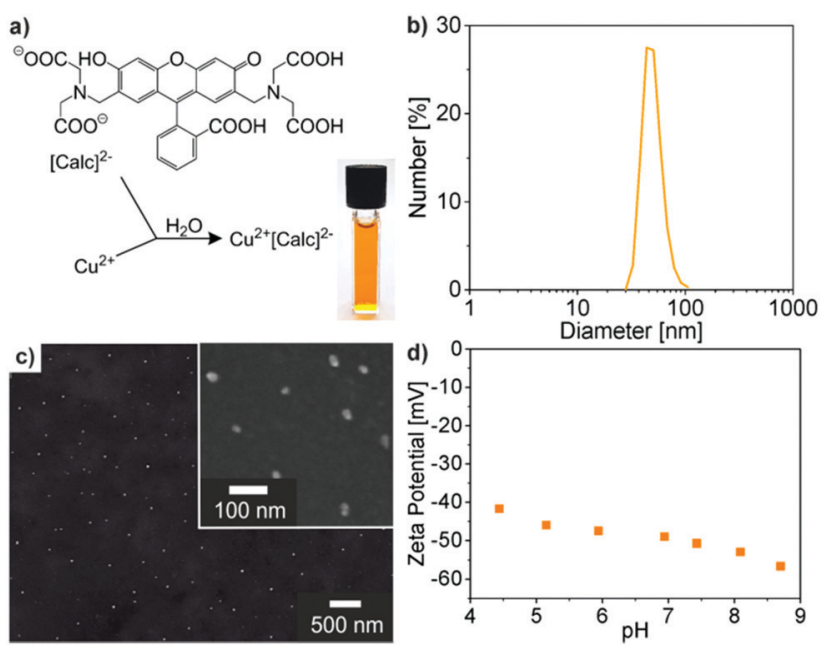

Fig. $2 \mathrm{Cu}^{2+}[\mathrm{Calc}]^{2-} \mathrm{IOH}-\mathrm{NPs}$ : (a) scheme of reaction and photo of as-prepared suspension in water, (b) hydrodynamic diameter according to DLS analysis in water, (c) particle size according to SEM at different scale of magnification, (d) zeta potential of aqueous suspension. 

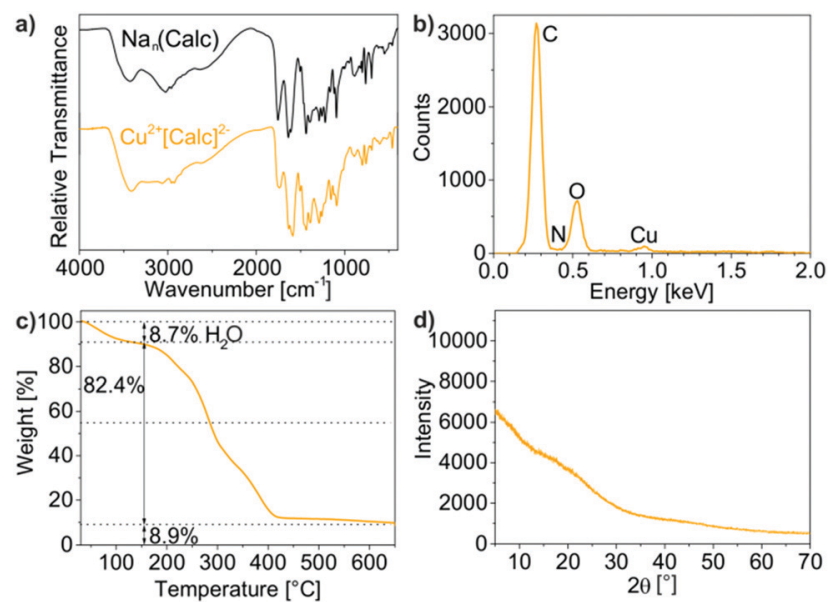

Fig. 3 Composition of the as-prepared $\mathrm{Cu}^{2+}[\mathrm{Calc}]^{2-} \mathrm{IOH}-\mathrm{NPs}$ : (a) FT-IR spectra (with $\mathrm{Na}_{n}$ (Calc) ( $n=2-3$ ) as a reference), (b) EDX, (c) TG, (d) XRD.

as suitable for sufficient electrostatic stabilization. ${ }^{17}$ Consequently, colloidally highly stable suspensions with concentrations up to $3 \mathrm{mg} \mathrm{mL}{ }^{-1}$ can be obtained that do not show any precipitation over periods of several weeks of storage (Fig. 2a). Here, it needs to be noted that specific surface stabilizers are not required.

The chemical composition of the as-prepared $\mathrm{Cu}^{2+}[\mathrm{Calc}]^{2-}$ IOH-NPs was examined by energy-dispersive X-ray analysis (EDX), Fourier-transform infrared spectroscopy (FT-IR), thermogravimetry (TG), and elemental analysis (EA). EDX qualitatively evidences the presence of all expected elements, namely $\mathrm{Cu} / \mathrm{C} / \mathrm{N} / \mathrm{O}$ (Fig. 3b). Quantification is not possible due to the limited significance in regard of light elements (C, N, O). FT-IR confirms the presence of calcein. A comparison of the $\mathrm{Cu}^{2+}[\mathrm{Calc}]^{2-}$ IOH-NPs with $\mathrm{Na}_{n}$ (Calc) $(n=2-3)$ as the starting material indicates very similar vibrations including $\nu(\mathrm{O}-\mathrm{H}): 3500-2900 \mathrm{~cm}^{-1}, \nu(\mathrm{C}-\mathrm{H})$ : 2900-2700 $\mathrm{cm}^{-1}, \nu(\mathrm{C}=\mathrm{O}): 1800-1600 \mathrm{~cm}^{-1}$, as well as the fingerprint area: $1600-800 \mathrm{~cm}^{-1}$ (Fig. 3a). A slight shift of the $\mathrm{C}=$ O-related vibrations of the IOH-NPs to lower wavenumbers $\left(1759 \rightarrow 1735 \mathrm{~cm}^{-1}, 1637 \rightarrow 1631 \mathrm{~cm}^{-1}, 1610 \rightarrow 1585 \mathrm{~cm}^{-1}\right)$ points to the coordination of the carboxylate group to the metal cation. The broadening of all vibrations in comparison to the reference can be ascribed to the non-crystallinity of the $\mathrm{Cu}^{2+}[\mathrm{Calc}]^{2-} \mathrm{IOH}-\mathrm{NPs}$, which was as well confirmed by X-ray powder diffraction (XRD) (Fig. 3d).

TG was performed to verify the total organic content of the $\mathrm{Cu}^{2+}[\mathrm{Calc}]^{2-}$ IOH-NPs (Fig. 3c). Thermal decomposition was observed to proceed in two steps. A first step up to $150{ }^{\circ} \mathrm{C}$ with a weight loss of $9 \%$ can be attributed to residual water adhered to the IOH-NPs. Thereafter, decomposition with $82 \mathrm{wt} \%$ (90 wt\% without water) related to total organics combustion occurred at $150-430{ }^{\circ} \mathrm{C}$ and fits very well with the calculated value $91 \%$ for the composition $\mathrm{Cu}^{2+}[\mathrm{Calc}]^{2-}$. Finally, the thermal residue was indentified via XRD as $\mathrm{CuO}$, so that the thermal decomposition can be ascribed to the following reaction:

$$
\mathrm{Cu}\left(\mathrm{C}_{30} \mathrm{H}_{24} \mathrm{~N}_{2} \mathrm{O}_{13}\right)+30 \mathrm{O}_{2} \rightarrow \mathrm{CuO}+30 \mathrm{CO}_{2}+\mathrm{N}_{2}+12 \mathrm{H}_{2} \mathrm{O}
$$

Finally, EA was performed to determine the composition of $\mathrm{Cu}^{2+}[\mathrm{Calc}]^{2-}$ and results in $\mathrm{C} / \mathrm{H} / \mathrm{N}$ contents of $53 \mathrm{wt} \% \mathrm{C}$, $4 \mathrm{wt} \% \mathrm{H}, 2 \mathrm{wt} \% \mathrm{~N}$, and a solid remain of $41 \mathrm{wt} \%$, which fits well with the calculated values (53 wt\% C, 4 wt $\%$ H, 4 wt $\%$ N, 39 wt $\%$ solid remain).

Although the $\mathrm{Cu}^{2+}[\mathrm{Calc}]^{2-}$ IOH-NPs represent a new type of compound, the use of calcein was inspired by nickel-calcein coordination complexes developed by Imato. ${ }^{6 a-c}$ In comparison to these dissolved coordination complexes, the here presented nanoparticles already show an emission intensity twice as high in the presence of histamine (see Section 3.6). Moreover, the IOH-NPs offer the option of immobilization on suitable substrates, which can be advantageous for practical handling in future histamine-detection kits. Nevertheless, the metal-calcein system has intrinsic weaknesses in the case of both the $\mathrm{Cu}^{2+}[\mathrm{Calc}]^{2-}$ IOH-NPs (in suspension) and the nickel-calcein coordination complexes (in solution). On the one hand, the emission intensity of calcein after histamine-driven release is still low. Moreover, the fluorescence of calcein in both the IOH-NPs and the coordination complexes is not completely quenched (see Section 3.6). Thus, the presence of histamine is only indicated by certain increase of the fluorescence intensity, which is much more difficult to detect than an off/on-like switching of the emission.

\section{$3.3 \mathrm{Ag}_{2}^{+}[\mathrm{Calc}]^{2-}$ IOH-NPs}

$\mathrm{Ag}_{2}{ }^{+}[\mathrm{Calc}]^{2-}$ was selected aiming at a lower solubility of carboxylate-functionalized dye anions in combination with $\mathrm{Ag}^{+}$and the resulting better control of the particle size. These IOH-NPs were prepared similar to $\mathrm{Cu}^{2+}[\mathrm{Calc}]^{2-}$ by injection of a solution of $\mathrm{AgNO}_{3}$ to a solution of $\mathrm{Na}_{n}$ (Calc) $(n=2-3)$ (Fig. 4a). According to DLS and SEM, the particle size of the as-prepared IOH-NPs was determined to $18 \pm 6 \mathrm{~nm}$ and $10 \pm 4 \mathrm{~nm}$, respectively (Fig. $4 \mathrm{~b}$ and c). With -50 to $-55 \mathrm{mV}$ at pH 5 to 10 (Fig. $4 \mathrm{~d}$ ), the zeta potential is even more negative than for $\mathrm{Cu}^{2+}[\mathrm{Calc}]^{2-}$.
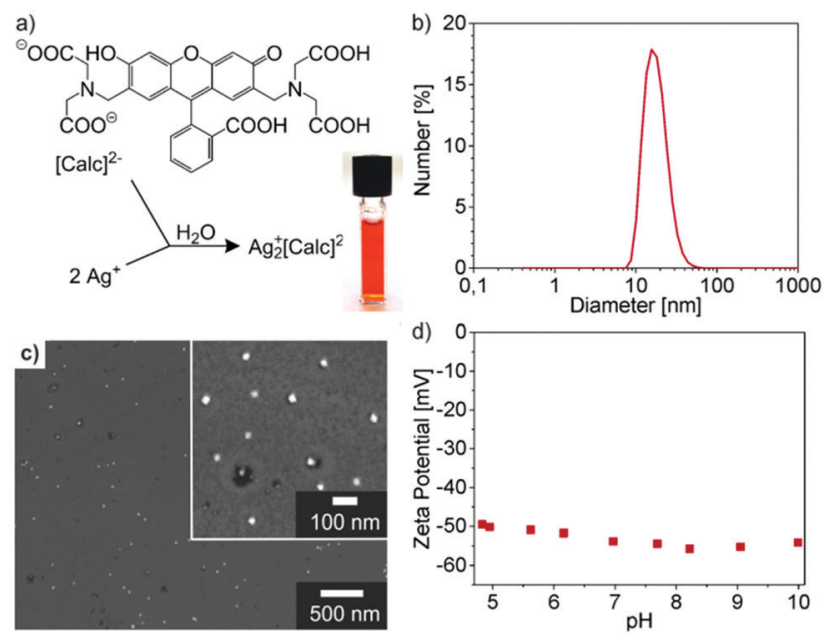

Fig. $4 \mathrm{Ag}_{2}{ }^{+}[\mathrm{Calc}]^{2-} \mathrm{OOH}-\mathrm{NPs}$ : (a) scheme of reaction and photo of as-prepared suspension in water, (b) hydrodynamic diameter according to DLS analysis in water, (c) particle size according to SEM at different scales of magnification, (d) zeta potential of aqueous suspension. 

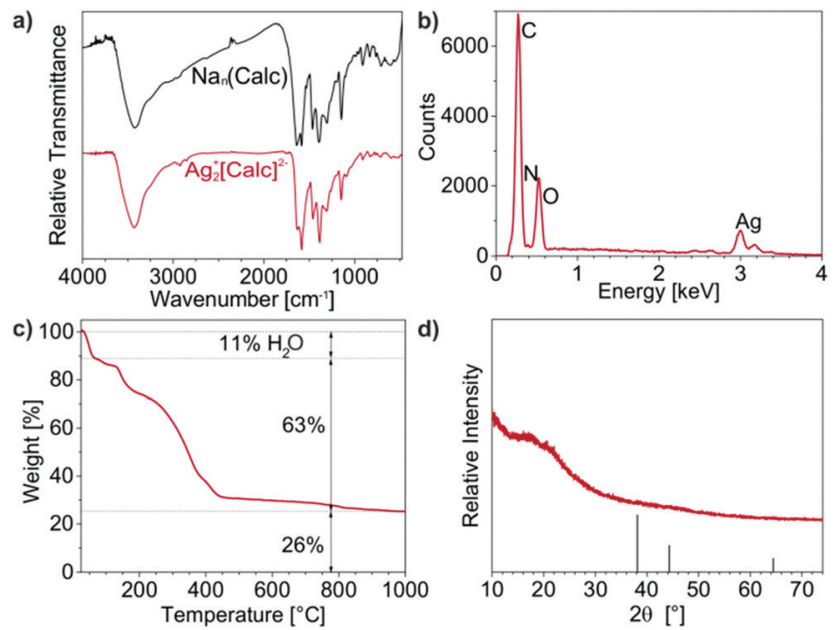

Fig. 5 Composition of the as-prepared $\mathrm{Ag}_{2}{ }^{+}[\mathrm{Calc}]^{2-}$ IOH-NPs: (a) FT-IR spectra (with $\mathrm{Na}_{n}$ (Calc) ( $n=2-3$ ) as a reference), (b) EDX, (c) TG, (d) XRD (with $\mathrm{Ag}$ as a reference, ICDD 03-065-2871).

Both the lower solubility and the higher charging of $\mathrm{Ag}_{2}{ }^{+}[\mathrm{Calc}]^{2-}$ result in a lower particle size and an even higher colloidal stability (Fig. 4a) as compared to $\mathrm{Cu}^{2+}[\mathrm{Calc}]^{2-}$.

In regard of the chemical composition of the amorphous $\mathrm{Ag}_{2}{ }^{+}[\mathrm{Calc}]^{2-}$ IOH-NPs, EDX evidences the presence of all expected elements (Ag/C/N/O) (Fig. 5b and d). FT-IR, again, shows the characteristic vibrations of calcein and - similar to $\mathrm{Cu}^{2+}[\mathrm{Calc}]^{2-}$ - a slight shift of the $\mathrm{C}=$ O-related vibrations to lower wavenumbers $\left(1639 \rightarrow 1629 \mathrm{~cm}^{-1}, 1587 \rightarrow 1583 \mathrm{~cm}^{-1}\right.$, $1394 \rightarrow 1384 \mathrm{~cm}^{-1}$ ) indicating the coordination to the cation (Fig. 5a). TG indicates a thermal release of water up to $150{ }^{\circ} \mathrm{C}$ with a weight loss of $11 \%$ (Fig. $5 \mathrm{c}$ ). The total organics combustion with a sample weight loss of $63 \mathrm{wt} \%$ (71 wt\% without water, $150-430{ }^{\circ} \mathrm{C}$ ) relates to calcein and is in good agreement with calculated value (74\%). XRD evidences the thermal residue as elemental silver. In sum, the thermal decomposition can be rationalized as follows:

$$
\mathrm{Ag}_{2}\left(\mathrm{C}_{30} \mathrm{H}_{24} \mathrm{~N}_{2} \mathrm{O}_{13}\right)+28 \frac{1}{2} \mathrm{O}_{2} \rightarrow 2 \mathrm{Ag}+30 \mathrm{CO}_{2}+\mathrm{N}_{2}+12 \mathrm{H}_{2} \mathrm{O}
$$

According to $\mathrm{EA}, \mathrm{Ag}_{2}{ }^{+}[\mathrm{Calc}]^{2-}$ shows $\mathrm{C} / \mathrm{H} / \mathrm{N}$ contents of $40 \mathrm{wt} \% \mathrm{C}, 3 \mathrm{wt} \% \mathrm{H}, 3 \mathrm{wt} \% \mathrm{~N}$ and a solid remain of $55 \mathrm{wt} \%$ that fit well with the expectation (43 wt $\%$ C, 3 wt $\%$ H, 3 wt $\%$ N, 51 wt\% solid remain).

Aiming at lower solubility and smaller particle sizes, $\mathrm{Ag}_{2}^{+}[\mathrm{Calc}]^{2-}$ is indeed superior to $\mathrm{Cu}^{2+}[\mathrm{Calc}]^{2-}$. However, it needs to be noticed that $\mathrm{Ag}_{2}^{+}[\mathrm{Calc}]^{2-}$ is highly sensitive to daylight and heating. Both lead to a decomposition of the IOH-NPs with formation of elemental silver, which is a common observation for many silver salts. ${ }^{18}$ Only if $\mathrm{Ag}_{2}{ }^{+}[\mathrm{Calc}]^{2-}$ was strictly handled in darkness and dried at $0{ }^{\circ} \mathrm{C}$ by freeze drying, XRD does not indicate any Bragg peaks (Fig. 5d). Temperatures above room temperature as well as an exposition to daylight result in the formation of silver, which is indicated by a colour change from red to black as well as by the appearance of the Ag-related Bragg peaks. Although $\mathrm{Ag}_{2}{ }^{+}[\mathrm{Calc}]^{2-}$ outperforms $\mathrm{Cu}^{2+}[\mathrm{Calc}]^{2-}$ in terms

of particle size and emission intensity (see Section 3.6), its sensitivity to light is of course a severe disadvantage for practical handling.

\section{$3.4 \mathrm{Cu}_{2}{ }^{2+}[\mathrm{PTC}]^{4-}$ IOH-NPs}

The third example $-\mathrm{Cu}_{2}{ }^{2+}[\mathrm{PTC}]^{4-}$ - contains the perylene derivative perylenetetracarboxylate (Fig. 6a). Perylenes are generally known for their exceptionally high emission intensity and quantum yields near $100 \%$ as well as for their high photochemical and thermal stability. ${ }^{19}$ Due to the flat shape of the perylenes and the resulting extensive $\pi$-stacking, their fluorescence is typically efficiently quenched in the solid state. Both features fluorescence quenching in the solid state and intense emission in solution exactly fit with the concept of the here intended fluorescence-based histamine detection.

In principle, $\mathrm{Cu}_{2}{ }^{2+}[\mathrm{PTC}]^{4-} \mathrm{IOH}-\mathrm{NPs}$ were prepared similar to $\mathrm{Cu}^{2+}[\mathrm{Calc}]^{2-}$ and $\mathrm{Ag}_{2}{ }^{+}[\mathrm{Calc}]^{2-}$ (Fig. 6a). To obtain the $[\mathrm{PTC}]^{4-}$ anion, however, perylene-3,4,9,10-tetracarboxylic dianhydride (PTCDA) as the starting material needs to be treated in alkaline solution to open the intramolecular cyclic anhydride.

The characterization of the as-prepared $\mathrm{Cu}_{2}{ }^{2+}[\mathrm{PTC}]^{4-}$ IOH-NPs in terms of particle size and chemical composition was performed as discussed for $\mathrm{Cu}^{2+}[\mathrm{Calc}]^{2-}$ and $\mathrm{Ag}_{2}{ }^{+}[\mathrm{Calc}]^{2-}$. Thus, the size was determined by DLS and SEM, resulting in $129 \pm 8 \mathrm{~nm}$ and $104 \pm 9 \mathrm{~nm}$ (Fig. 6b and c). The larger size relates to the rod-like shape of the $\mathrm{Cu}_{2}{ }^{2+}[\mathrm{PTC}]^{4-}$ IOH-NPs and originates from the as-expected $\pi$-stacking of the perylene-type anions (Fig. 6c). Despite of the larger particle size, the negative zeta potential of -13 to $-40 \mathrm{mV}$ at $\mathrm{pH} 5$ to 10 guarantees high colloidal stability (Fig. 6d). Qualitatively, EDX confirms the presence of $\mathrm{Cu} / \mathrm{C} / \mathrm{O}$ (Fig. 7b), whereas FT-IR evidences the presence of PTC (Fig. 7a). Hence, the characteristic vibrations of $\mathrm{Cu}_{2}{ }^{2+}[\mathrm{PTC}]^{4-}$ are in accordance with the starting material after opening the anhydride functionality by alkaline treatment. Similar to calcein, the shift of all $\mathrm{C}=$ O-related vibrations $\left(1556 \rightarrow 1543 \mathrm{~cm}^{-1}\right.$,
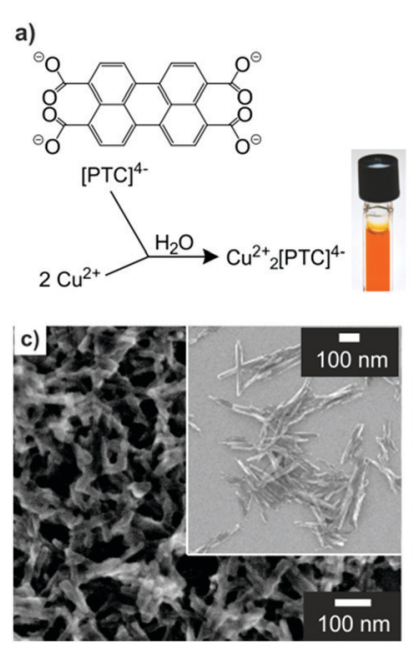

Fig. $6 \mathrm{Cu}_{2}{ }^{2+}[\mathrm{PTC}]^{4-} \mathrm{IOH}-\mathrm{NPs}$ : (a) scheme of reaction and photo of as-prepared suspension in water, (b) hydrodynamic diameter according to DLS analysis in water, (c) particle size according to SEM at different scales of magnification, (d) zeta potential of aqueous suspension. 

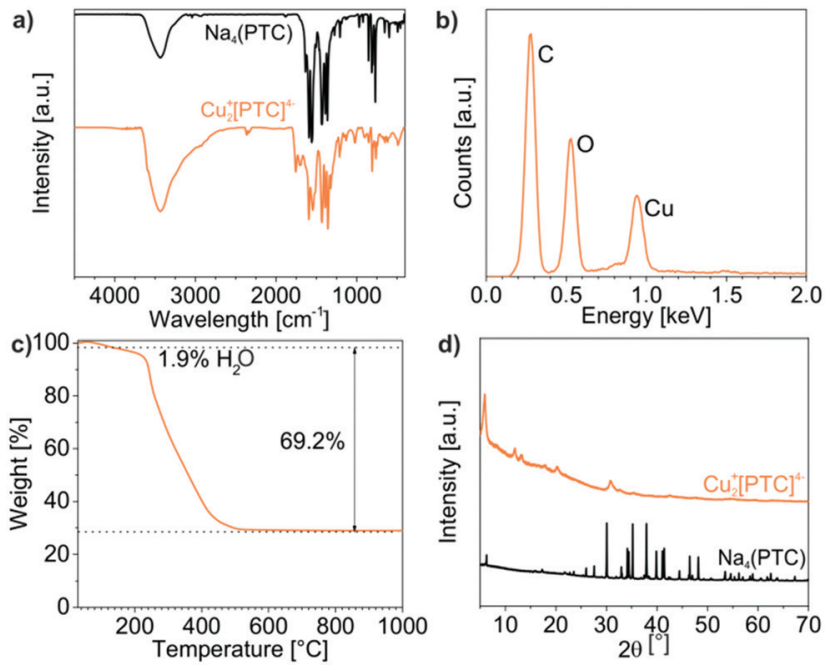

Fig. 7 Composition of the as-prepared $\mathrm{Cu}_{2}{ }^{2+}[\mathrm{PTC}]^{4-}$ IOH-NPs: (a) FT-IR spectra (with $\mathrm{Na}_{4}$ (PTC) as a reference), (b) EDX, (c) TG, (d) XRD (with the starting material $\mathrm{Na}_{4}(\mathrm{PTC})$ as reference).

$1435 \rightarrow 1527 \mathrm{~cm}^{-1}$ ) indicates the coordination of PTC to the cation (Fig. 7a). After the release of water (up to $150{ }^{\circ} \mathrm{C}, 1.9 \mathrm{wt} \%$ ), TG indicates the thermal decomposition of PTC with a weight loss of $69 \%$ at $150-430{ }^{\circ} \mathrm{C}(70 \%$ without water, Fig. $7 \mathrm{~d})$, which fits well with the expectation ( $71 \mathrm{wt} \%$ ). According to XRD, copper(II) oxide remains as the residue, so that the thermal decomposition can be ascribed to the following reaction:

$$
\mathrm{Cu}_{2}\left(\mathrm{C}_{24} \mathrm{H}_{8} \mathrm{O}_{8}\right)+23 \mathrm{O}_{2} \rightarrow 2 \mathrm{CuO}+24 \mathrm{CO}_{2}+4 \mathrm{H}_{2} \mathrm{O}
$$

According to $\mathrm{EA}, \mathrm{Cu}_{2}{ }^{2+}[\mathrm{PTC}]^{4-}$ shows $\mathrm{C} / \mathrm{H} / \mathrm{N}$ contents of $50 \mathrm{wt} \% \mathrm{C}, 2 \mathrm{wt} \% \mathrm{H}, 0 \mathrm{wt} \% \mathrm{~N}$ and a solid remain of $48 \mathrm{wt} \%$ that fit well with the expectation $(52 \mathrm{wt} \% \mathrm{C}, 1 \mathrm{wt} \% \mathrm{H}, 0 \mathrm{wt} \% \mathrm{~N}$, $47 \mathrm{wt} \%$ solid remain).

$\mathrm{Cu}_{2}{ }^{2+}[\mathrm{PTC}]^{4-}$ differentiates from the previously presented IOH-NPs in regard of several aspects. First of all, the compound shows considerable Bragg peaks, which indicate the crystallinity of these IOH-NPs (Fig. 7d). The observed spacing between the Bragg peaks with distances of $1 d, 1 / 2 d, 1 / 3 d$ ( $d$ : lattice distance) is often observed for perylene derivatives and related to the $\pi$-stacking of these molecules. ${ }^{20} \mathrm{~A}$ comparison with the starting material, furthermore, validates the observed Bragg peaks not to stem from $\mathrm{Na}_{4}$ (PTC) and an incomplete reaction or insufficient purification. In regard of the fluorescence features, finally, $\mathrm{Cu}_{2}{ }^{2+}[\mathrm{PTC}]^{4-}$ indeed shows a 6-to-7-times higher emission intensity in the presence of histamine than $\mathrm{Cu}^{2+}[\mathrm{Calc}]^{2-}$ (see Section 3.6), which confirms the benefit of PTC. The emission of $\mathrm{Cu}_{2}^{2+}[\mathrm{PTC}]^{4-}$ in the solid nanoparticles, on the other hand, is still not totally quenched, so that the difference in emission intensity in the absence and in the presence of histamine requires further improvement.

\section{$3.5 \mathrm{Ag}_{4}^{+}[\mathrm{PTC}]^{4-}$ IOH-NPs}

$\mathrm{Ag}_{4}{ }^{+}[\mathrm{PTC}]^{4-}$ as the fourth example combines those inorganic cations and functional organic anions that can be considered
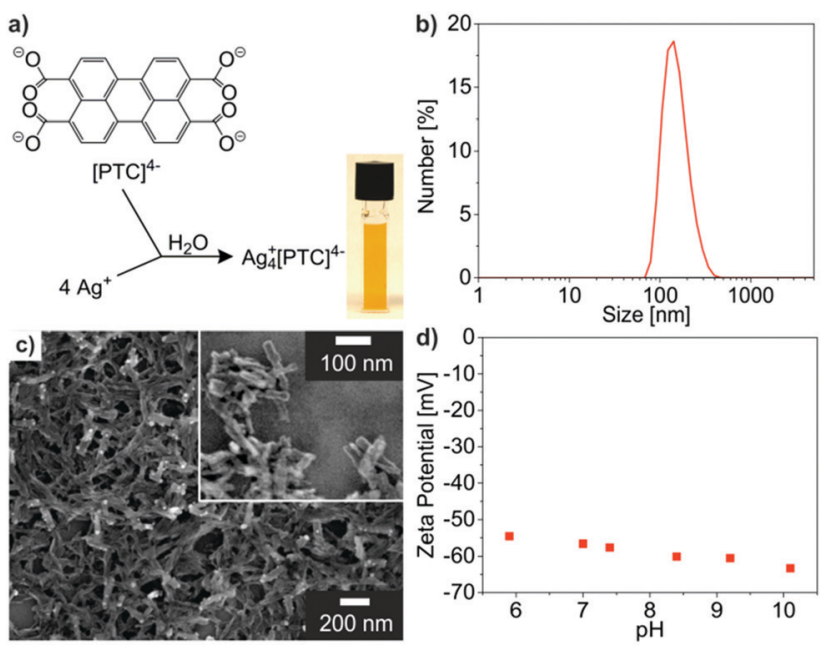

Fig. $8 \mathrm{Ag}_{4}{ }_{4}[\mathrm{PTC}]^{2-} \mathrm{IOH}-\mathrm{NPs}$ : (a) scheme of reaction and photo of as-prepared suspension in water, (b) hydrodynamic diameter according to DLS analysis in water, (c) particle size according to SEM at different scales of magnification, (d) zeta potential of aqueous suspension.

most promising. In this regard, $\mathrm{Ag}^{+}$is optimal as it forms insoluble carboxylates in water and since it forms highly stable and soluble amine complexes in water. Moreover, $[\mathrm{PTC}]^{4-}$ allows efficient fluorescence quenching in the solid nanoparticles due to $\pi$-stacking and most intense emission after its release into solution. With these prerequisites, maximum difference in emission intensity and optimal differentiation of presence or absence of histamine should be possible.

$\mathrm{Ag}_{4}{ }^{+}[\mathrm{PTC}]^{4-}$ IOH-NPs were prepared like $\mathrm{Cu}_{2}{ }^{2+}[\mathrm{PTC}]^{4-}$ (Fig. 8a). DLS and SEM of the $\mathrm{Ag}_{4}{ }^{+}[\mathrm{PTC}]^{4-}$ IOH-NPs indicate mean particle sizes of $155 \pm 9 \mathrm{~nm}$ and $140 \pm 8 \mathrm{~nm}$ (Fig. 8b and c). Similar to $\mathrm{Cu}_{2}{ }^{2+}[\mathrm{PTC}]^{4-}$, this large size relates to the $\pi$-stacking of the perylene-type anions and a rod-like shape of the $\mathrm{Ag}_{4}^{+}[\mathrm{PTC}]^{4-}$ IOH-NPs (Fig. 8c). The zeta potential with -54 to $-64 \mathrm{mV}$ at pH 5 to 10 turned out as highly negative and guarantees good colloidal stability (Fig. 8d). In regard of the chemical composition, EDX qualitatively confirms the presence of $\mathrm{Ag} / \mathrm{C} / \mathrm{O}$ (Fig. 9b). FT-IR evidences the presence of PTC (Fig. 9a). The shift of all $\mathrm{C}=$ O-related vibrations $\left(1589 \rightarrow 1585 \mathrm{~cm}^{-1}, 1556 \rightarrow 1537 \mathrm{~cm}^{-1}\right)$ validate the coordination of PTC to the cation (Fig. 9a). TG and EA were again used to quantify the chemical composition. Thus, thermal release of water (up to $150{ }^{\circ} \mathrm{C}, 3 \mathrm{wt} \%$ ) and thermal decomposition of PTC were observed $\left(50 \%\right.$ at $150-430{ }^{\circ} \mathrm{C}$ or $51 \%$ without water, Fig. 9d). The latter value fits well with the expectation (50 wt\%). XRD indicates elemental silver as solid residue, resulting in the following decomposition reaction:

$$
\mathrm{Ag}_{4}\left(\mathrm{C}_{24} \mathrm{H}_{8} \mathrm{O}_{8}\right)+22 \mathrm{O}_{2} \rightarrow 4 \mathrm{Ag}+24 \mathrm{CO}_{2}+4 \mathrm{H}_{2} \mathrm{O}
$$

EA of $\mathrm{Ag}_{4}{ }_{4}^{+}[\mathrm{PTC}]^{4-}$ shows C/H/N contents of $34 \mathrm{wt} \% \mathrm{C}, 1 \mathrm{wt} \% \mathrm{H}$, $0 \mathrm{wt} \% \mathrm{~N}$ and a solid remain of $65 \mathrm{wt} \%$ that fit well with the expected values $(34 \mathrm{wt} \% \mathrm{C}, 1 \mathrm{wt} \% \mathrm{H}, 0 \mathrm{wt} \% \mathrm{~N}, 65 \mathrm{wt} \%$ solid remain). Like $\mathrm{Cu}_{2}{ }^{2+}[\mathrm{PTC}]^{4-}$, the $\mathrm{Ag}_{4}{ }^{+}[\mathrm{PTC}]^{4-}$ IOH-NPs show considerable Bragg peaks with distances of $1 d, 1 / 2 d, 1 / 3 d$ $(d \text { : lattice distance })^{20}$ related to the $\pi$-stacking of the perylenes 

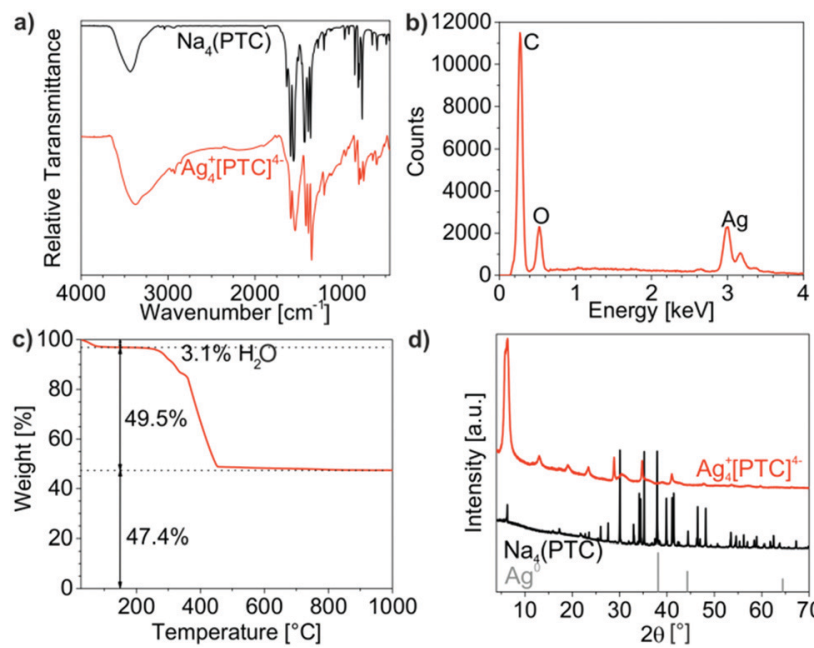

d)

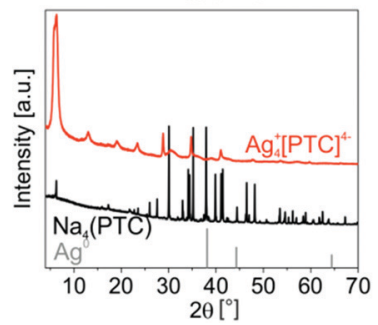

Fig. 9 Composition of the as-prepared $\mathrm{Ag}_{4}{ }^{+}[\mathrm{PTC}]^{4-}$ IOH-NPs: (a) FT-IR spectra (with $\mathrm{Na}_{4}$ (PTC) as a reference), (b) EDX, (c) TG, (d) XRD (with $\mathrm{Na}_{4}$ (PTC) (starting material) and Ag (ICDD 03-065-2871) as references).

molecules (Fig. 9d). Taken together, the chemical composition of the $\mathrm{Ag}_{4}^{+}[\mathrm{PTC}]^{4-}$ IOH-NPs is well confirmed. Even more important, $\mathrm{Ag}_{4}{ }^{+}[\mathrm{PTC}]^{4-}-$ in contrast to $\mathrm{Ag}_{2}{ }^{+}[\mathrm{Calc}]^{2-}-$ is not sensitive to daylight and slight heating. Although prepared at $60{ }^{\circ} \mathrm{C}$ and although stored in daylight, the as-prepared $\mathrm{Ag}_{4}{ }^{+}[\mathrm{PTC}]^{4-}$ IOH-NPs do not show any Bragg peaks of elemental silver (Fig. 9d). In regard of the fluorescence properties, finally, the $\mathrm{Ag}_{4}^{+}[\mathrm{PTC}]^{4-}$ IOH-NPs do not show any emission due to fluorescence quenching in the solid state, whereas the released $[\mathrm{PTC}]^{4-}$ shows highly intense emission (see Section 3.6).

\subsection{IOH-NP-based fluorescence sensing of histamine}

Subsequent to the preparation and characterization of $\mathrm{Cu}^{2+}[\mathrm{Calc}]^{2-}$, $\mathrm{Ag}_{2}{ }^{+}[\mathrm{Calc}]^{2-}, \mathrm{Cu}_{2}{ }^{2+}[\mathrm{PTC}]^{4-}$ and $\mathrm{Ag}_{4}{ }^{+}[\mathrm{PTC}]^{4-}$ as novel compounds, the fluorescence features and the applicability of these $\mathrm{IOH}^{-}$ NPs to detect histamine were evaluated as a proof-of-theconcept. In general, it is intended to realize IOH-NPs that show only weak emission due to fluorescence quenching in the solid state (Fig. 10a and c). In the presence of histamine, however, the IOH-NPs are dissolved with release of $[\mathrm{Calc}]^{2-}$ and $[\mathrm{PTC}]^{4-}$, which thereafter show bright fluorescence in solution (Fig. 10b and d). The dissolution of the IOH-NPs is driven by the coordination of the respective cation with histamine (Fig. 10). Hence, the cation has to be selected in regard of two tasks: (i) the cation needs to form insoluble IOH-NPs with the carboxylate-functionalized dye anions; (ii) In the presence of histamine, stable and soluble coordination complexes need to be obtained. In this regard, the selected $\mathrm{Cu}^{2+}$ and $\mathrm{Ag}^{+}$are most promising.

The fluorescence of calcein and a detectable variation of the emission intensity in the presence of certain metal cations was already suggested for sensing applications. Thus, calceincontaining silica nanoparticles were used to detect $\mathrm{Ca}^{2+}$ in blood serum. ${ }^{21}$ Moreover, calcein-containing polymer thinfilms were reported for cystein sensing, ${ }^{22}$ and calcein-based fluorescence sensors were also described for specific protein

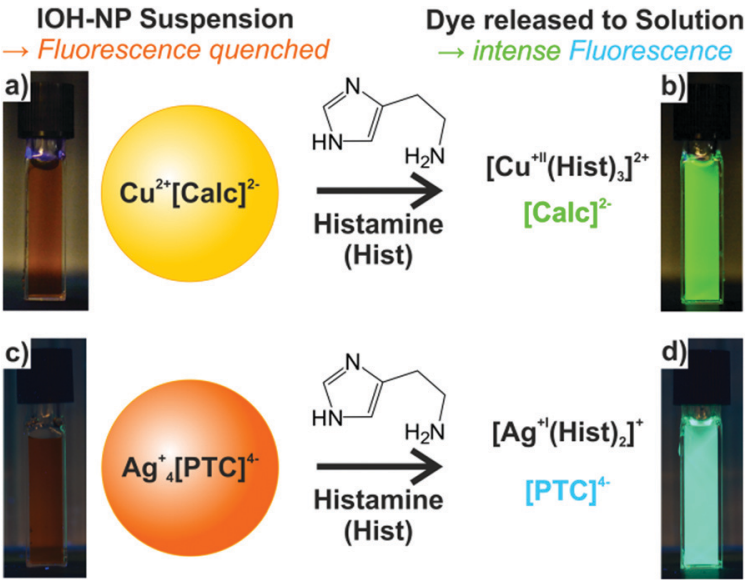

Fig. 10 Histamine detection by $1 \mathrm{OH}-\mathrm{NPs}$ with quenched fluorescence of the solid nanoparticles ( $a$ and $c$ ) and intense fluorescence upon histaminedriven release ( $c$ and $d$ ) of the fluorescent dye into the solution: ( $a$ and $b$ ) $\mathrm{Cu}^{2+}[\mathrm{Calc}]^{2-} \mathrm{IOH}-\mathrm{NPs}$; (c and d) $\mathrm{Ag}_{4}{ }^{+}[\mathrm{PTC}]^{4-} \mathrm{IOH}-\mathrm{NPs}$ (aqueous solutions under UV excitation).

targeting. ${ }^{23}$ Finally, histamine sensing was suggested using calcein coordination complexes in solution. Thus, the emission of calcein was reported to be low if coordinated to $\mathrm{Ni}^{2+}$ and to increase significantly in the presence of histamine. Histamine coordinates more strongly to $\mathrm{Ni}^{2+}$, which initiates the release of calcein showing intense emission in solution thereafter. ${ }^{6 a-c}$ Drawbacks of this concept include the dilution in the volume of the solution and a rather limited increase of the emission intensity by a factor of 2-3 upon addition of $100 \mu \mathrm{M}$ of histamine. Such low increase of the emission intensity can be hardly used for reliable fluorescence detection. ${ }^{6 a-c}$ In fact, an off/on-like fluorescence with totally quenched fluorescence in absence of histamine and intense emission in the presence of histamine would be optimal for reliable detection.

The here presented novel $\mathrm{Cu}^{2+}[\mathrm{Calc}]^{2-}$ and $\mathrm{Ag}_{2}{ }^{+}[\mathrm{Calc}]^{2-}$ IOH-NPs also contain calcein but represent solid nanoparticles that are practically easier to handle and that show a significantly higher fluorescence increase than coordination complexes in solution. In contrast to calcein, perylenetetracarboxylate (PTC) is here first suggested for fluorescence detection of biogenic amines such as histamine. In principle, all IOH-NPs $\mathrm{Cu}^{2+}[\mathrm{Calc}]^{2-}, \mathrm{Ag}_{2}{ }^{+}[\mathrm{Calc}]^{2-}, \mathrm{Cu}_{2}{ }^{2+}[\mathrm{PTC}]^{4-}, \mathrm{Ag}_{4}{ }^{+}[\mathrm{PTC}]^{4-}-$ show the intended effect of limited fluorescence due to certain quenching in the solid nanoparticles and significantly more intense emission after histamine-driven dissolution of the IOH-NPs with release of [Calc $]^{2-}$ and $[\mathrm{PTC}]^{4-}$ (Fig. 10). The effect was quantified by fluorescence spectroscopy and addition of histamine with concentrations of 10,100 , and $1000 \mu \mathrm{M}$ (Fig. 11). All measurements were performed at identical concentrations of the IOH-NPs $(10 \mu \mathrm{M})$ and at identical spectrometric conditions (e.g. slit widths). All IOH-NPs exhibit an emission maximum at $510-520 \mathrm{~nm}$, and they show good correlation between histamine concentration and emission intensity (Fig. 11).

$\mathrm{Cu}^{2+}[\mathrm{Calc}]^{2-}$ IOH-NPs show a 6-fold increase in emission intensity upon addition of $100 \mu \mathrm{M}$ of histamine (Fig. 11a), 

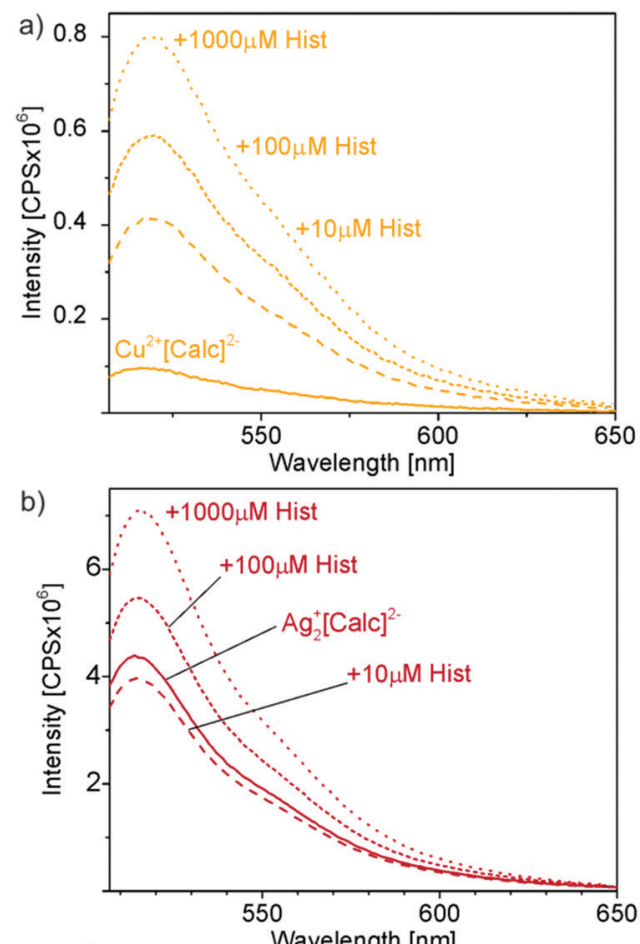

c)

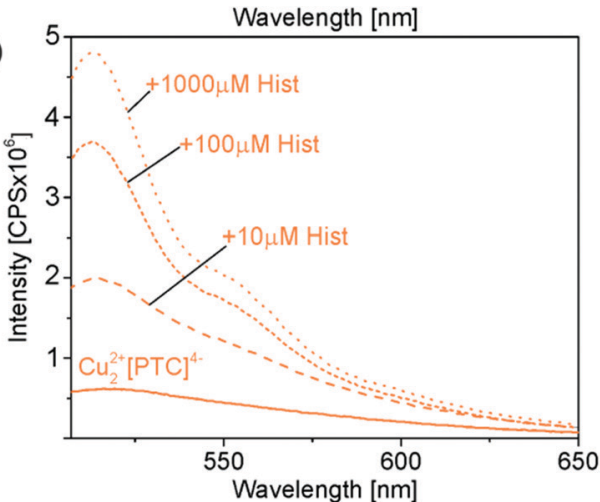

d)

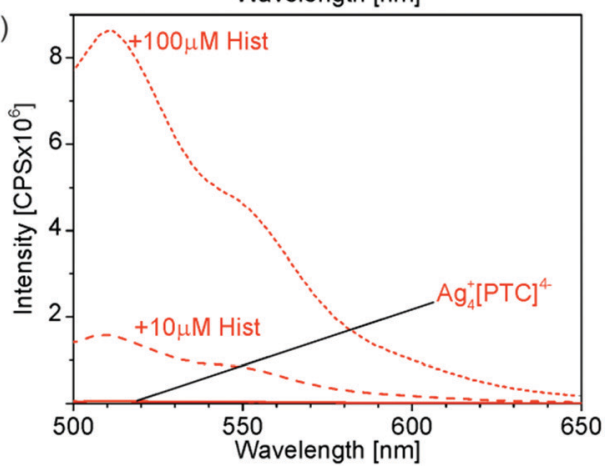

Fig. 11 Correlation of emission intensity and histamine concentration for: (a) $\mathrm{Cu}^{2+}[\mathrm{Calc}]^{2-}$, (b) $\mathrm{Ag}_{2}{ }^{+}[\mathrm{Calc}]^{2-}$, (c) $\mathrm{Cu}_{2}{ }^{2+}[\mathrm{PTC}]^{4-}$, (d) $\mathrm{Ag}_{4}{ }^{+}[\mathrm{PTC}]^{4-}$. All suspensions contain $10 \mu \mathrm{M}$ of $1 \mathrm{OH}-\mathrm{NPs}$. The emission intensity (CPS: counts per second) of all samples was measured before and after addition of $0-1000 \mu \mathrm{M}$ of histamine.

which is already doubled in comparison to the data reported for nickel-calcein coordination complexes in solution. ${ }^{6 a-c}$ Similar to the coordination complexes in solution, however, $\mathrm{Cu}^{2+}[\mathrm{Calc}]^{2-}$ also exhibits certain emission in the absence of histamine, which reduces the reliability of the analysis. On the other hand, the IOH-NPs offer the advantage of unprecedentedly high calcein content (90 wt\%) per nanoparticle and allow an immobilization on a suitable substrate, which can be preferred in terms of practical handling for histamine-detection kits.

Although indeed more insoluble than $\mathrm{Cu}^{2+}[\mathrm{Calc}]^{2-}$ and despite of even smaller particle diameters, $\mathrm{Ag}_{2}{ }^{+}[\mathrm{Calc}]^{2-}$ turned out as insufficient for histamine detection. On the one hand, these IOH-NPs are highly sensitive to light, and on the other hand, the emission is increased only by a factor of about 1.5 upon addition of $100 \mu \mathrm{M}$ of histamine (Fig. 11b). Moreover, it needs to be noticed that the emission after addition of $10 \mu \mathrm{M}$ of histamine is similar to the emission in absence of histamine. Although samples and measurements were performed in darkness, this finding can be ascribed to the light sensitivity of $\mathrm{Ag}_{2}{ }^{+}[\mathrm{Calc}]^{2-}$. The formation of elemental silver, of course, also supports a release of calcein and as well results in significant emission in the absence of any histamine.

The fluorescence features of $\mathrm{Cu}_{2}{ }^{2+}[\mathrm{PTC}]^{4-}$ more-or-less compare to $\mathrm{Cu}^{2+}[\mathrm{Calc}]^{2-}$ (Fig. 11a and c). Thus, a 6-times higher emission intensity is observed after addition of $100 \mu \mathrm{M}$ of histamine. Although the absolute emission intensity of $\mathrm{Cu}_{2}{ }^{2+}[\mathrm{PTC}]^{4-}$ is about 10-times higher than for $\mathrm{Cu}^{2+}[\mathrm{Calc}]^{2-}$ at identical conditions of measurement, the promising effect is neglected by the emission of $\mathrm{Cu}_{2}^{2+}[\mathrm{PTC}]^{4-}$ in the absence of histamine, which unfortunately is also about 10-times higher than for $\mathrm{Cu}^{2+}[\mathrm{Calc}]^{2-}$ (Fig. 11a and c).

$\mathrm{Ag}_{4}{ }^{+}[\mathrm{PTC}]^{4-}$ IOH-NPs, finally, turn out as most promising and show a massive increase in emission intensity upon addition of $100 \mu \mathrm{M}$ of histamine (Fig. 11d). Here, the fluorescence is indeed almost totally quenched for the solid nanoparticles with an emission of only $5 \times 10^{4}$ CPS (CPS: counts per second) remaining (Fig. 11d). In the presence of $100 \mu \mathrm{M}$ of histamine, the emission intensity increases by two orders of magnitude to $8.8 \times 10^{6} \mathrm{CPS}\left(\mathrm{Ag}_{4}^{+}[\mathrm{PTC}]^{4-}\right)$, resulting in a remarkable factor of 180 (Fig. 11d). Even $10 \mu \mathrm{M}$ of histamine result in a 35-times higher emission than in the absence of histamine. All in all, $\mathrm{Ag}_{4}^{+}[\mathrm{PTC}]^{4-}$ significantly outperforms the calcein-based IOH-NPs, which is even more obvious when comparing the emission of all

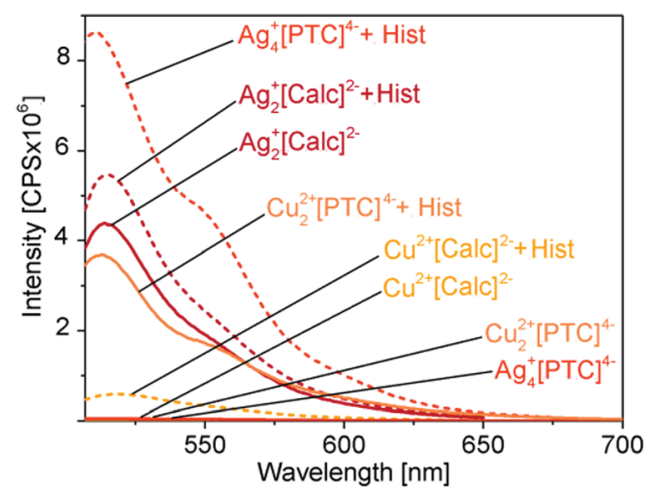

Fig. 12 Comparison of fluorescence response upon histamine addition to $\mathrm{Cu}^{2+}[\mathrm{Calc}]^{2-}, \mathrm{Ag}_{2}{ }^{+}[\mathrm{Calc}]^{2-}, \mathrm{Cu}_{2}{ }^{2+}[\mathrm{PTC}]^{4-}$ and $\mathrm{Ag}_{4}^{+}[\mathrm{PTC}]^{4-} \mathrm{IOH}-\mathrm{NP}$ suspensions (CPS: counts per second). All samples at identical concentrations of $1 \mathrm{OH}-\mathrm{NPs}(10 \mu \mathrm{M})$ and histamine $(100 \mu \mathrm{M})$. 
IOH-NPs in the absence and in the presence of $100 \mu \mathrm{M}$ of histamine (Fig. 12). In fact, the intended off/on-emission without/with histamine is realized with $\mathrm{Ag}_{4}{ }^{+}[\mathrm{PTC}]^{4-} \mathrm{IOH}-\mathrm{NPs}$.

The strong fluorescence effect of the $\mathrm{Ag}_{4}{ }^{+}[\mathrm{PTC}]^{4-} \mathrm{IOH}-\mathrm{NPs}$ can be ascribed to the almost complete quenching in the solid state, the stability of the silver histamine coordination complex, the high dye load per nanoparticle (50 wt\% of PTC in $\mathrm{Ag}_{4}^{+}[\mathrm{PTC}]^{4-}$ ), and the superior emission of the perylene derivative. Based on its off/on-emission characteristics, the novel $\mathrm{Ag}_{4}{ }^{+}[\mathrm{PTC}]^{4-}$ seems highly promising for a sensing of biogenic amines. Subsequent to its first synthesis and characterization as well as the proof-of-the-concept in regard of a fluorescencebased detection of histamine, the sensing effect needs to be validated next in regard of a differentiation of biogenic amines such as serotonin, dopamine, gamma-aminobutyric acid, adrenaline, heparin, or thyroxin.

\section{Conclusions and outlook}

Four novel inorganic-organic hybrid nanoparticles (IOH-NPs) are presented including $\mathrm{Cu}^{2+}[\mathrm{Calc}]^{2-}, \mathrm{Ag}_{2}{ }^{+}[\mathrm{Calc}]^{2-}$ (Calc: calcein, $\mathrm{C}_{30} \mathrm{H}_{24} \mathrm{~N}_{2} \mathrm{O}_{13}$ ), $\mathrm{Cu}_{2}{ }^{2+}[\mathrm{PTC}]^{4-}$ and $\mathrm{Ag}_{4}{ }^{+}[\mathrm{PTC}]^{4-}$ (PTC: perylenetetracarboxylate, $\mathrm{C}_{24} \mathrm{H}_{8} \mathrm{O}_{8}$ ). The saline IOH-NPs contain extremely high dye loads of calcein $\left(90 \mathrm{wt} \%\right.$ in $\mathrm{Cu}^{2+}[\mathrm{Calc}]^{2-}, 70 \mathrm{wt} \%$ in $\mathrm{Ag}_{2}{ }^{+}[\mathrm{Calc}]^{2-}$ ) and the perylene derivative (77 $\mathrm{wt} \%$ in $\mathrm{Cu}_{2}{ }^{2+}[\mathrm{PTC}]^{4-}$, $50 \mathrm{wt} \%$ in $\mathrm{Ag}_{4}^{+}[\mathrm{PTC}]^{4-}$ ). They are insoluble in water and can be prepared by straightforward aqueous synthesis. $\mathrm{Cu}^{2+}[\mathrm{Calc}]^{2-}$ and $\mathrm{Ag}_{2}{ }^{+}[\mathrm{Calc}]^{2-}$ exhibit a spherical shape with diameters of $27 \pm$ $8 \mathrm{~nm}$ and $10 \pm 4 \mathrm{~nm}$, whereas $\mathrm{Cu}_{2}{ }^{2+}[\mathrm{PTC}]^{4-}$ and $\mathrm{Ag}_{4}{ }^{+}[\mathrm{PTC}]^{4-}$ have a rod-like shape with a length of 100 to $140 \mathrm{~nm}$ due to the $\pi$-stacking of the perylene molecules. Due to electrostatic charging as indicated by zeta potentials higher than $-20 \mathrm{mV}$ at $\mathrm{pH} 5-10$, all IOH-NPs are colloidally highly stable in aqueous suspension. Their chemical composition was validated by different methods, such as energy-dispersive X-ray analysis, Fourier-transform infrared spectroscopy, thermogravimetry, and elemental analysis.

$\mathrm{Cu}^{2+}[\mathrm{Calc}]^{2-}, \mathrm{Ag}_{2}{ }^{+}[\mathrm{Calc}]^{2-}, \mathrm{Cu}_{2}{ }^{2+}[\mathrm{PTC}]^{4-}$ and $\mathrm{Ag}_{4}{ }^{+}[\mathrm{PTC}]^{4-}$ can be used to detect biogenic amines, which is shown as a proof-of-the-concept for histamine. Whereas the fluorescence is low due to partial quenching in the solid nanoparticles, the fluorescent dyes calcein and perylenetetracarboxylate are released into the solution upon addition of histamine, which forms highly stable coordination complexes with $\mathrm{Cu}^{2+}$ and $\mathrm{Ag}^{+}$. $\mathrm{Cu}^{2+}[\mathrm{Calc}]^{2-}, \mathrm{Ag}_{2}{ }^{+}[\mathrm{Calc}]^{2-}$ and $\mathrm{Cu}_{2}{ }^{2+}[\mathrm{PTC}]^{4-}$ exhibit several weaknesses in regard of the fluorescence detection of histamine. On the one hand, they still show certain emission as solid nanoparticles in the absence of histamine. On the other hand, the increase in emission is limited to a factor of about 6 for an addition of $100 \mu \mathrm{M}$ of histamine in the case of $\mathrm{Cu}^{2+}[\mathrm{Calc}]^{2-}$ and $\mathrm{Cu}_{2}{ }^{2+}[\mathrm{PTC}]^{4-}$. Despite of a higher particle quality, $\mathrm{Ag}_{2}{ }^{+}[\mathrm{Calc}]^{2-}$ turned out as insufficient due to a minor histamine-driven increase of emission and high light sensitivity resulting in a decomposition of the compound with formation of elemental silver. The novel $\mathrm{Ag}_{4}{ }^{+}[\mathrm{PTC}]^{4-} \mathrm{IOH}-\mathrm{NPs}$, however, show a superior effect with a 180-times higher emission upon addition of $100 \mu \mathrm{M}$ of histamine and total quenching of the fluorescence in the solid state. Such on/off-behaviour is most promising in regard of a reliable fluorescence detection. In contrast to $\mathrm{Ag}_{2}^{+}[\mathrm{Calc}]^{2-}$, moreover, $\mathrm{Ag}_{4}{ }^{+}[\mathrm{PTC}]^{4-}$ does not show any light sensitivity.

Based on the histamine-driven boost in emission, the novel $\mathrm{Ag}_{4}{ }^{+}[\mathrm{PTC}]^{4-}$ IOH-NPs seem highly promising for fluorescence sensing of histamine and the detection of allergic reactions. With a fluorescence increase of a factor of 180, moreover, $\mathrm{Ag}_{4}{ }^{+}[\mathrm{PTC}]^{4-}$ IOH-NPs significantly outperform yet known nickel-calcein coordination complexes showing a 2-3-times higher emission only (both after addition of $100 \mu \mathrm{M}$ histamine). Most preferably, the here presented IOH-NPs will be immobilized on suitable substrates and used for ex vivo application with blood serum. Beside histamine and allergy diagnostics, the $\mathrm{Ag}_{4}{ }^{+}[\mathrm{PTC}]^{4-}$ IOH-NPs could be also used for fluorescence sensing of other biogenic amines (e.g., serotonin, dopamine, gamma-aminobutyric acid, adrenaline, heparin, or thyroxine). A verification regarding selectivity and differentiation is currently in progress.

\section{Conflicts of interest}

There are no conflicts to declare.

\section{Acknowledgements}

The authors acknowledge the Bundesministerium für Wirtschaft (BMWi) for funding within the joint project "Nanopartikel für die Allergie-relevante Analytik (NanoARA)". Furthermore, we are grateful to Prof. Dr Henk Garritsen, Helmholtz-Zentrum für Infektionsforschung (HZI) Braunschweig, for excellent cooperation.

\section{References}

1 European Centre for Allergy Research (ECARF), www.ecarf. org, annual report 2017.

2 F. E. Simons, L. R. Ardusso, M. B. Bilò, Y. M. El-Gamal, D. K. Ledford, J. Ring, M. Sanchez-Borges, G. E. Senna, A. Sheikh and B. Y. Thong, World Allergy Organ. J., 2011, 4, 13.

3 H. J. Gould and B. J. Sutton, Nat. Rev. Immunol., 2008, 8, 205. 4 R. L. Thurmond, E. W. Gelfand and P. J. Dunford, Nat. Rev. Drug Discovery, 2008, 7, 41.

5 (a) Y. Oshikawa, K. Furuta, S. Tanaka and A. Ojida, Anal. Chem., 2016, 88, 1526; (b) A. L. de Week, M. L. Sanz, P. M. Gamboa, W. Aberer, J. Bienvenu, M. Blanca, P. Demoly, D. G. Ebo, L. Mayorga, G. Monneret and J. Sainte-Laudy, Int. Arch. Allergy Immunol., 2008, 146, 177; (c) A. L. De Week, M. L. Sanz, P. M. Gamboa, W. Aberer, J. Bienvenu, M. Blanca, P. Demoly, D. G. Ebo, L. Mayorga, G. Monneret and L. J. Sainte, J. Investig. Allergol. Clin. Immunol., 2008, 18, 143; (d) D. G. Ebo, C. H. Bridts, M. M. Hagendorens, N. E. Aerts, L. S. De Clerck and W. J. Stevens, Cytometry, Part B, 2008, 74, 201; (e) B. Eberlein-Konig, J. Rakoski, 
H. Behrendt and J. Ring, J. Investig. Allergol. Clin. Immunol., 2004, 14, 10.

6 (a) M. Ali, P. Ramirez, I. Duznovic, S. Nasir, S. Mafe and W. Ensinger, Colloids Surf., 2017, 150, 201; (b) D. Seto, T. Maki, N. Soh, K. Nakano, R. Ishimatsu and T. Imato, Talanta, 2012, 94, 36; (c) D. Seto, N. Soh, K. Nakano and T. Imato, Anal. Biochem., 2010, 404, 135; (d) X. Han, J. L. Jorgensen, A. Brahmandam, E. Schlette, Y. O. Huh, Y. Shi, S. Awagu and W. Chen, Arch. Pathol. Lab. Med., 2008, 132, 813.

7 H. Renz, T. Biedermann, A. Bufe, B. Eberlein, U. Jappe, M. Ollert, A. Petersen, J. Kleine-Tebbe, M. Raulf-Heimsoth, J. Saloga, T. Werfel and M. Worm, Allergy J., 2009, 19, 110.

8 (a) D. Jin, P. Xi, B. Wang, L. Zhang, J. Enderlein and A. M. van Oijen, Nat. Methods, 2018, 15, 1; (b) E. B. Ehlerding, P. Grodzinski, W. Cai and C. H. Liu, ACS Nano, 2018, 12, 2106; (c) X. Zhao, C.-X. Yang, L.-G. Chen and X.-P. Yan, Nat. Commun., 2017, 8, 14998.

9 (a) K. Y. Zhang, Q. Yu, H. Wei, S. Liu, Q. Zhao and W. Huang, Chem. Rev., 2018, 118, 1770; (b) J. Huang and N. Gretz, ChemistryOpen, 2017, 6, 456; (c) S. M. Ng, M. Koneswaran and R. Narayanaswamy, RSC Adv., 2016, 6, 21624; (d) O. S. Wolfbeis, Chem. Soc. Rev., 2015, 44, 4743; (e) J. Yao, M. Yang and Y. Duan, Chem. Rev., 2014, 114, 6130.

10 (a) X. Feng, J. Ashley, T. Zhou, A. Halder and Y. Sun, RSC $A d v ., 2018,8$, 2365; (b) T. Deng, Y. Peng, R. Zhang, J. Wang, J. Zhang, Y. Gu, D. Huang and D. Deng, ACS Appl. Mater. Interfaces, 2017, 9, 11405; (c) S. Khan, L. S. A. Carneiro, M. S. Vianna, E. C. Romani and R. Q. Aucelio, J. Lumin., 2017, 182, 71.

11 (a) Z. Wu, E. Xu, A. Jiao, Z. Jin and J. Irudayaraj, $R S C A d v$., 2017, 7, 44933; (b) K. M. A. El-Nour, E. T. A. Salam, H. M. Soliman and A. S. Orabi, Nanoscale Res. Lett., 2017, $12,1$.
12 (a) J. G. Heck, J. Napp, S. Simonato, J. Möllmer, M. Lange, H. R. Reichardt, R. Staudt, F. Alves and C. Feldmann, J. Am. Chem. Soc., 2015, 137, 7329; (b) J. G. Heck, K. Rox, H. Lünsdorf, T. Lückerath, N. Klaassen, E. Medina, O. Goldmann and C. Feldmann, ACS Omega, 2018, 3, 8589; (c) J. Napp, M. A. Markus, J. G. Heck, C. Dullin, W. Möbius, D. Gorpas, C. Feldmann and F. Alves, Theranostics, 2018, 8, 6367.

13 (a) M. Poß, J. Napp, O. Niehaus, R. Pöttgen, F. Alves and C. Feldmann, J. Mater. Chem. C, 2015, 3, 3860; (b) M. Poß, R. J. Tower, J. Napp, L. C. Appold, T. Lammers, F. Alves, C.-C. Glüer, S. Boretius and C. Feldmann, Chem. Mater., 2017, 29, 3547; (c) M. Poß, E. Zittel, C. Seidl, A. Meschkov, L. Muñoz, U. Schepers and C. Feldmann, Adv. Funct. Mater., 2018, 28, 1801074.

14 B. L. Neumeier, M. Khorenko, F. Alves, O. Goldmann, J. Napp, U. Schepers, H. M. Reichardt and C. Feldmann, ChemNanoMat, 2018, 4, 1.

15 L. Neumeier, J. Heck, C. Feldmann, W. Lindenmaier, K. Dittmar and H. Garritsen, DE 102017002642.4, EP3376228, 2017.

16 V. K. LaMer and R. H. Dinegar, J. Am. Chem. Soc., 1950, $72,4847$.

17 R. Vogel, A. K. Pal, S. Jambhrunkar, P. Patel, S. S. Thakur, E. Reátegui, H. S. Parekh, P. Saá, A. Stassinopoulos and M. F. Broom, Sci. Rep., 2017, 7, 17479.

18 O. V. Mikhailov and V. K. Polovnyak, J. Coord. Chem., 1992, 27, 267.

19 Z. Chen, U. Baumeister, C. Tschierske and F. Wuerthner, Chem. - Eur. J., 2007, 13, 450.

20 G. R. Desiraju and A. Gavezzotti, J. Chem. Soc., Chem. Commun., 1989, 621.

21 X. Hun and Z. Zhang, Microchim. Acta, 2007, 159, 255.

22 M. Li, Y. Fu and L. Jin, Dalton Trans., 2017, 46, 7284.

23 R. Imamura, N. Murata, T. Shimanouchi, K. Yamashita, M. Fukuzawa and M. Noda, Sensors, 2017, 17, 1630. 